\title{
Immunohistochemical expression of Cyclooxygenase 2 reflects the proliferative activity in the epithelium of odontogenic lesions
}

\author{
Vani Verma, Chetana Chandrashekar, Raghu Radhakrishnan, Monica Charlotte Solomon
}

Department of Oral Pathology and Microbiology Manipal College of Dental Sciences, Manipal, Manipal Academy of Higher Education Manipal 576104, Karnataka, India

\section{Abstract}

Purpose: Odontogenic cysts and tumors comprise a major component of lesions of the oral and maxillofacial region. The pathogenesis of these lesions involves the interaction between the odontogenic epithelium and the ectomesenchyme. However, the clinical behavior of these biological entities is unpredictable. The aim of this study was to evaluate the role of Cyclooxygenase $2(\mathrm{COX}-2)$ in the pathogenesis and prognostication of odontogenic lesions.

Materials and Methods: In this study formalin-fixed paraffin-embedded tissue section of Odontogenic Keratocyst $(n=10)$ Dentigerous cyst $(n=10)$, Radicular cyst $(n=10)$ and unicystic ameloblastoma $(n=10)$ were immunohistochemically stained with COX-2 (NCL2-COX-2$4 \mathrm{H} 12$ ) and with $\mathrm{Ki} 67$ (Ki-67 GM001) using standard staining protocols. The cytoplasmic expression of COX-2 in all the lesions was semi-quantitatively assessed. The pattern of expression of COX-2 among the different odontogenic lesions was statistical analyzed using the ANOVA test and the chi-square test.

Results: All the 40 odontogenic lesions that were evaluated expressed COX-2 immunohistochemically. A high number of odontogenic epithelial cells expressed COX-2 in most of the odontogenic keratocyst, radicular cyst and unicystic ameloblastomas. The expression of COX-2 was significantly $(p=0.036)$ higher in Unicystic Ameloblastomas and Radicular cyst compared to that of Odontogenic Keratocyst and the dentigerous cyst.
Conclusion: The recognition that expression of COX-2 by odontogenic epithelial cells may indeed shed a new light on the biological mechanisms involved in the development of these benign yet aggressive lesions of the jaws. An insight into the molecular interactions occurring in the odontogenic epithelium will aid in better management of these lesions.

Citation: Verma, et al. (2022). Immunohistochemical expression of Cylooxygenase 2 reflects the proliferative activity in the epithelium of odontogenic lesions. Dentistry 3000. 1:a001 doi:10.5195/d3000.2022.205 Received: July 12, 2021 Accepted: September 30, 2021

Published: January 10, 2022

Copyright: $\bigcirc 2022$ Verma, et al. This is an open access article licensed under a Creative Commons Attribution Work 4.0 United States License.

Email:monica.charlotte@manipal.edu

\section{Introduction}

Odontogenic lesions are the most common benign lesions that occur within the jaw bones. These lesions are derived from the epithelium associated with the formation of the hard and soft tissues of the tooth. Around $52.3-70.7 \%$ of the cysts that are submitted to an oral pathology biopsy service are Radicular cysts,
16.6-21.3\% are Dentigerous cyst 5.4\% - $17.4 \%$ are Odontogenic keratocyst (5.4-17.4\%) [1].

The Radicular cyst also called the periapical cyst is the most common odontogenic cystic lesion. The World Health Organization classification of head and neck tumors describes Radicular cyst as a cyst of inflammatory origin associated with non-vital teeth [2]. It arises due to activation of the cell rests of Malassez that are present in the periodontal ligament due to an inflammatory stimulus. Radicular cysts present as a swelling of the jaw and may be associated with pain/loosening of tooth, root resorption of the affected tooth and displacement of the adjacent teeth [3]. 
The most common developmental odontogenic cysts are Dentigerous cysts. Dentigerous cyst is an odontogenic cyst that is attached to the cervical region of an unerupted tooth and envelops the crown [2]. This cyst arises due to the separation of the dental follicle from around the crown of unerupted teeth. The dentigerous cysts usually develop in relation to an impacted mandibular third molar tooth. Long standing dentigerous cysts can cause root resorption, bone expansion and local destruction [4]

The Odontogenic keratocyst is an odontogenic cyst characterized by a thin regular lining of parakeratinized stratified squamous epithelium with palisading hyperchromatic basal cells. [2]. Odontogenic keratocyst originates from the remnants of the dental lamina and exhibits typical cystic lining of 6 to 10 cell layer thickness. The odontogenic keratocyst is recognized for its intrinsic growth potential and its high rate of recurrence [5].

Unicystic ameloblastoma is a variant of intraosseous ameloblastoma that occurs as a single cystic cavity with or without luminal proliferation [2]. Unicystic ameloblastomas usually occur in younger individuals.

Although a variant of ameloblastoma it possesses a less aggressive growth pattern compared to a solid ameloblastoma. On histologic examination they show a typical ameloblastomatous epithelium lining part of the cyst cavity, with or without luminal and/or mural tumor proliferation $[5,6]$.

Cyclooxygenase 2 is a $72 \mathrm{kda}$

cytokine-inducible enzyme that is situated in the nuclear membrane and the rough endoplasmic reticulum of the human cell $[7,8]$. COX- 2 is an important enzyme responsible for the synthesis of the prostanoids; prostaglandins, prostacyclin and thromboxane [9]. During inflammation, there is an abundance of COX-2 in macrophages and other inflammatory cells [10]. An upregulation of COX-2 is brought about by growth factors and inflammatory mediators such as lipopolysaccharides and tumor necrosis factors [8].

An over expression of COX-2 has been associated with cell proliferation, apoptosis, angiogenesis and enhanced invasiveness [11,12]. The expression of COX-2 has been associated with precancerous lesion and with the malignant tumors of the head and neck regions.[13]. However, the role of COX-2 in the clinical behavior of odontogenic lesions is less explored [14, 15, 16,17]. The aim of this study was to evaluate the expression of COX-2 in odontogenic lesions and assess its role in the clinical behaviour of these lesions.

\section{Material and Methods}

This study was approved by the Ethics Committee of Kasturba Medical College Manipal (108/2016). Forty formalin fixed paraffin embedded tissue specimens; Odontogenic
Keratocyst ( $n=10)$ Dentigerous cyst $(n=10)$ Radicular cyst $(n=10)$ and Unicystic Ameloblastomas ( $n=10$ ) were retrieved from the archives of the department. Five-micron thick sections were cut from each block and the sections were stained with hematoxylin and eosin. Tissue sections were reviewed to confirm the diagnosis and to determine the adequacy of the tissue for immunohistochemical staining.

Immunohistochemical Procedure

Four-micron thick sections were cut from the FFPE tissue blocks and were taken onto aminopropyl triethoxy silane (APES, Sigma-Aldrich Co. St. Louis, USA) coated slides.

Sections were deparaffinized through 3 changes of xylene and hydrated through descending grades of alcohol (100\%, 95\%, 70\%). The endogenous peroxidase activity was quenched by incubating the sections in $3 \% \mathrm{H}_{2} \mathrm{O}_{2}$ for 10 minutes.

Antigen retrieval was carried out using a domestic pressure cooker method with sodium citrate solution ( $\mathrm{pH}$ 6.0). Following antigen retrieval, the tissue sections were allowed to cool at room temperature for 20 minutes. To block the non-specific binding sites the section were treated with protein block (Novacastra Lieca Biosystem, Newcastle) for 5 mins. The sections were then incubated in mouse monoclonal COX -2 primary antibody (NovacastraTM Mouse Monoclonal Antibody Cyclooxygenase-2: NCL-COX-2-4H12) 
at 1:1000 dilution (with tris buffer, $\mathrm{pH}$

7.6) for 60 minutes at $37^{\circ} \mathrm{C}$ in a moist humidifying chamber.

The antigen-antibody reaction was developed by incubating the section with secondary antibody (Secondary antibody Novolink polymer Antimouse (gG-Poly-HRP) for $\mathbf{3 0}$ minutes at room temperature in a moist chamber. The antigen-antibody reaction was detected using the chromogen Diaminobenzidine and its buffer. The sections were counterstained in Mayer's hematoxylin, were dehydrated through ascending grades of alcohol (70\%, 95\% and $100 \%)$ cleared in xylene and mounted with Dibutylphthalate Xylene (DPX). For positive control tissue sections of normal buccal mucosa and colon carcinoma was used. For a negative control, a tissue section was stained in the similar manner except that instead of the primary monoclonal antibody, the tris buffer was used.

For Ki-67

Four-micron thick sections were cut from the FFPE tissue blocks (one each of Dentigerous cyst, Radicular cyst, Odontogenic Keratocyst and ameloblastoma) and were taken onto aminopropyl triethoxy silane (APES, Sigma-Aldrich Co. St. Louis, USA) coated slides. Sections were deparaffinized through 3 changes of xylene and hydrated through descending grades of alcohol $(100 \%$, $95 \%, 70 \%)$. Antigen retrieval was performed using tris EDTA buffer at $\mathrm{pH}$ 9.0, Endogenous peroxide was neutralized by treating the sections with pre-diluted $3 \%$ hydrogen peroxide. Following this, sections were incubated with pre diluted mouse monoclonal primary antibodyKi -67 (clone Ki-67 GM001, Pathnsitu, USA) for 1 hour at room temperature in a moist humidifying chamber.

Then the sections were incubated with pre diluted primary target binder (PolyExcel Target Binder, PathnSitu, USA) at room temperature for 10 minutes. Slides were then incubated with secondary antibody pre diluted (PolyExcel Poly HRP, PathnSitu,USA), at room temperature for 10 minutes. The peroxidase activity was developed with Diamino Benzidine Tetra Hydrochloride (DAB). Finally, the sections were counter stained with Mayer's Haematoxylin, dehydrated, cleared, and mounted with Dibutylphthalate Xylene (DPX).

\section{Assessment of COX-2}

immunostaining

The expression of COX-2 was carried out in a semi-quantitative manner independently by two pathologists using a light microscope (Olympus BX41). Five high-power fields were observed for each case and the cells that showed a diffuse brown stain in the cytoplasm was considered positive for COX-2. The percentage of positive cells in the four fields was recorded, the mean percentage of positive cells in all the four fields was determined. The expression of COX-2 was scored as 0 (Absence of the stain), 1 ( $<25 \%$ of the cells were positive) 2 (25-50\% of the cells were positive), 3 (51-75\% of positive cells), and 4 ( $75-100 \%$ of positive cells).

The intensity of the expression of COX-2 was graded as 0 (Absence of the expression), 1 (weak expression), 2 (moderate expression) and 3 (strong expression). The Total score was obtained by adding the score of percentage of positive cells and the score of staining intensity as suggested by Mendes et al (modified) [15]. A total score of 0 was given if there was complete absence of the expression of COX-2. And finally, the expression of COX-2 was regarded as low expression when the sum of the score for the percentage of positive cells and the intensity of the expression ranged from 1-4 and the expression of COX-2 was regarded as a high expression when the sum of the score for the percentage of positive cells and the intensity of the expression ranged from 5-7.

\section{Statistical Analysis}

All statistical analyses were performed using the Statistical Package for Social Sciences (SPSS) version 16.0. 
Descriptive analysis was carried out for patient characteristics. Inter-observer variability was assessed using Cohen's kappa coefficient and was found to be of good reproducibility (0.92). The association between expression of COX-2 and the odontogenic lesions was assessed using a one-way ANOVA analysis method and the Chi Square test. A $p$ value of $<0.05$ was regarded as statistically significant.

\section{Results}

In this study the expression of cyclooxygenase- 2 was evaluated in 40 cases of odontogenic cysts and tumors that included 10 cases of dentigerous cysts, 10 cases of Radicular cyst, 10 cases of odontogenic keratocyst and 10 cases of Unicystic Ameloblastoma. The age of the patients ranged from 10 years to 71 years (Mean age 31.5 years). Among the patients 27 of them were males and 13 of them were females. The clinico pathological details of all the odontogenic lesions along with their COX-2 expression pattern are given in Table 1. All the odontogenic lesions except one case of dentigerous cyst that were evaluated showed a mildsevere expression of COX-2 (Fig 1).

Among the dentigerous cysts in $4 / 10$ (40\%) cysts the mean percentage of

Table 1. Clinico-pathological details of the Odontogenic lesions and their COX-2 expression profile

\begin{tabular}{|c|c|c|c|c|c|c|c|c|}
\hline No. & Age & Gender & Site FDI Numbering system) & Odontogenic lesion & $\begin{array}{l}\text { Mean \% of Cells } \\
\text { expressing coX-2 }\end{array}$ & $\begin{array}{l}\text { Score for number of } \\
\text { cells expressing } \\
\text { cOX-2 }\end{array}$ & $\begin{array}{l}\text { Intensity of the } \\
\text { expression of } \\
\text { cox-2 }\end{array}$ & $\begin{array}{l}\text { Total Score of the } \\
\text { expression of COX- } \\
2\end{array}$ \\
\hline 1 & 22 & M & Right ramus of the mandible & Dentigerous cyst & 60 & 3 & 1 & 4 \\
\hline 2 & 38 & M & $11,21,22$ & Dentigerous cyst & 0 & 0 & 0 & 0 \\
\hline 3 & 12 & M & 47,46 & Dentigerous cyst & 25 & 1 & 1 & 2 \\
\hline 4 & 10 & M & & Dentigerous cyst & 11 & 2 & 2 & 4 \\
\hline 5 & 49 & $\mathrm{~F}$ & 48,47 & Dentigerous cyst & 40 & 3 & 1 & 4 \\
\hline 6 & 33 & $\mathrm{~F}$ & & Dentigerous cyst & 22 & 2 & 2 & 4 \\
\hline 7 & 20 & M & $47,46,45,44,43$ & Dentigerous cyst & 20 & 1 & 2 & 3 \\
\hline 8 & 18 & $\mathrm{~F}$ & 13,12 & Dentigerous cyst & 46 & 3 & 1 & 4 \\
\hline 9 & 47 & M & 11,22 & Dentigerous cyst & 17 & 1 & 2 & 3 \\
\hline 10 & 23 & M & $17----11--21$ & Dentigerous cyst & 20 & 1 & 2 & 3 \\
\hline 11 & 51 & M & 16 & Radicular cyst & 80 & 4 & 2 & 6 \\
\hline 12 & 23 & M & 21 & Radicular cyst & 85 & 4 & 2 & 6 \\
\hline 13 & 14 & $\mathrm{~F}$ & 36 & Radicular cyst & 40 & 2 & 2 & 4 \\
\hline 14 & 22 & M & 11 & Radicular cyst & 35 & 2 & 2 & 4 \\
\hline 15 & 65 & M & 13....21 & Radicular cyst & 79 & 4 & 2 & 6 \\
\hline 16 & 42 & M & 41--------31,32,33,32,35,36 & Radicular cyst & 90 & 4 & 2 & 6 \\
\hline 17 & 27 & $\mathrm{~F}$ & $22---25$ & Radicular cyst & 30 & 2 & 2 & 4 \\
\hline 18 & 25 & $\mathrm{~F}$ & 43-----------33 & Radicular cyst & 45 & 2 & 2 & 4 \\
\hline 19 & 14 & M & $15,14,13$ & Radicular cyst & 40 & 2 & 2 & 4 \\
\hline 20 & 45 & M & 12,11 & Radicular cyst & 43 & 2 & 2 & 4 \\
\hline 21 & 36 & M & 37,38 & Odontogenic Keratocyst & 20 & 1 & 1 & 2 \\
\hline 22 & 35 & $\mathrm{~F}$ & 47,48 & Odontogenic Keratocyst & 80 & 4 & 2 & 6 \\
\hline 23 & 71 & M & 47---41 & Odontogenic Keratocyst & 25 & 1 & 2 & 3 \\
\hline 24 & 33 & M & 38 & Odontogenic Keratocyst & 80 & 4 & 2 & 6 \\
\hline 25 & 71 & M & 47---------41 & Odontogenic Keratocyst & 30 & 2 & 2 & 4 \\
\hline 26 & 21 & M & Right ramus of the mandible & Odontogenic Keratocyst & 90 & 4 & 2 & 6 \\
\hline 27 & 15 & M & 47,46 & Odontogenic Keratocyst & 48 & 2 & 2 & 4 \\
\hline 28 & 13 & $\mathrm{~F}$ & 85---.--,42,,,,35 & Odontogenic Keratocyst & 50 & 2 & 2 & 4 \\
\hline 29 & 45 & M & & Odontogenic Keratocyst & 40 & 2 & 2 & 4 \\
\hline 30 & 34 & $\mathrm{~F}$ & & Odontogenic Keratocyst & 22 & 1 & 2 & 3 \\
\hline 31 & 28 & M & $32,33,34,35$ & Unicystic Ameloblastoma & 25 & 1 & 1 & 2 \\
\hline 32 & 31 & $\mathrm{~F}$ & 48,47 & Unicystic Ameloblastoma & 75 & 3 & 3 & 6 \\
\hline 33 & 17 & M & 48 & Unicystic Ameloblastoma & 80 & 4 & 2 & 6 \\
\hline 34 & 29 & M & 38 & Unicystic Ameloblastoma & 66 & 3 & 2 & 5 \\
\hline 35 & 42 & M & 48 & Unicystic Ameloblastoma & 22 & 1 & 1 & 2 \\
\hline 36 & 36 & M & 48 & Unicystic Ameloblastoma & 40 & 2 & 2 & 4 \\
\hline 37 & 17 & $\mathrm{~F}$ & 37,38 & Unicystic Ameloblastoma & 25 & 1 & 2 & 3 \\
\hline 38 & 24 & $\mathrm{~F}$ & 48.. & Unicystic Ameloblastoma & 85 & 4 & 2 & 6 \\
\hline 39 & 24 & $\mathrm{~F}$ & 48 & Unicystic Ameloblastoma & 60 & 3 & 3 & 6 \\
\hline 40 & 10 & M & 46 & Unicystic Ameloblastoma & 92 & 4 & 2 & 6 \\
\hline
\end{tabular}

odontogenic epithelial cells that expressed COX-2 ranged between $25 \%-50 \%$. Among the radicular cyst in $4 / 10(40 \%)$ the mean percentage of COX-2 positive cells was above $75 \%$. Among the odontogenic keratocysts in $3 / 10(30 \%)$ cases of percentage of COX-2 positive cells was above $75 \%$. Among the unicystic ameloblastomas in $3 / 10(30 \%)$ cases of percentage of COX-2 positive cells was above $75 \%$ (Fig 2).
Among the dentigerous cysts in 5/10 $(50 \%)$ cases the intensity of COX-2 expression was that of a moderate expression. All the 10/10 (100\%) cases of radicular cysts showed a moderate intensity of the expression of COX-2. Among the odontogenic keratocysts in 9/10 (90\%) cases showed a moderate intensity of the expression of the of COX-2. Among the unicystic ameloblastomas in $6 / 10$ (60\%) cases showed a moderate intensity of the expression of COX-2 (Fig 3) 


\section{口entistry $3 \square \square \square$}

Vol 10 No 1 (2022) DOI 10.5195/d3000.2022.205

Based on the overall expression of COX-2 in the odontogenic lesions, all the dentigerous cysts $10 / 10$ (100\%) cases, $6 / 10(60 \%)$ of the radicular cysts, $7 / 10(40 \%)$ of the odontogenic keratocysts and 4/10 (40\%) of unicystic ameloblastoma showed a low expression of COX-2. While 4/10 $(40 \%)$ of radicular cysts. $3 / 10(30 \%)$ of the odontogenic keratocysts and 6/10 $(60 \%)$ of unicystic ameloblastoma showed a high expression of COX-2 (Fig 4).

The comparison of the mean percentage of odontogenic epithelial cells expressing COX- 2 is given in Table 2 . The radicular cyst showed a high expression of COX-2 compared to dentigerous cyst or odontogenic keratocyst ( $p=0.031$ ) (Table 3). Among all the odontogenic lesions, Unicystic ameloblastoma showed a high expression of COX-2 ( $p=0.036)$ (Table 4). The comparison of the relative risk among all the odontogenic lesions is given in Table 5.

\section{Discussion}

COX-2, one of the isoforms of Cyclooxygenase is a key enzyme which mediates the process of inflammation. An up regulation of this enhances the synthesis of prostanoids especially Prostaglandin E $[18,19]$. The COX-2/PGE2 pathway, by enhancing cell survival and growth, has been suggested to play a role in suppression of apoptosis and enhancing cell survival and growth [20]. This study evaluated the
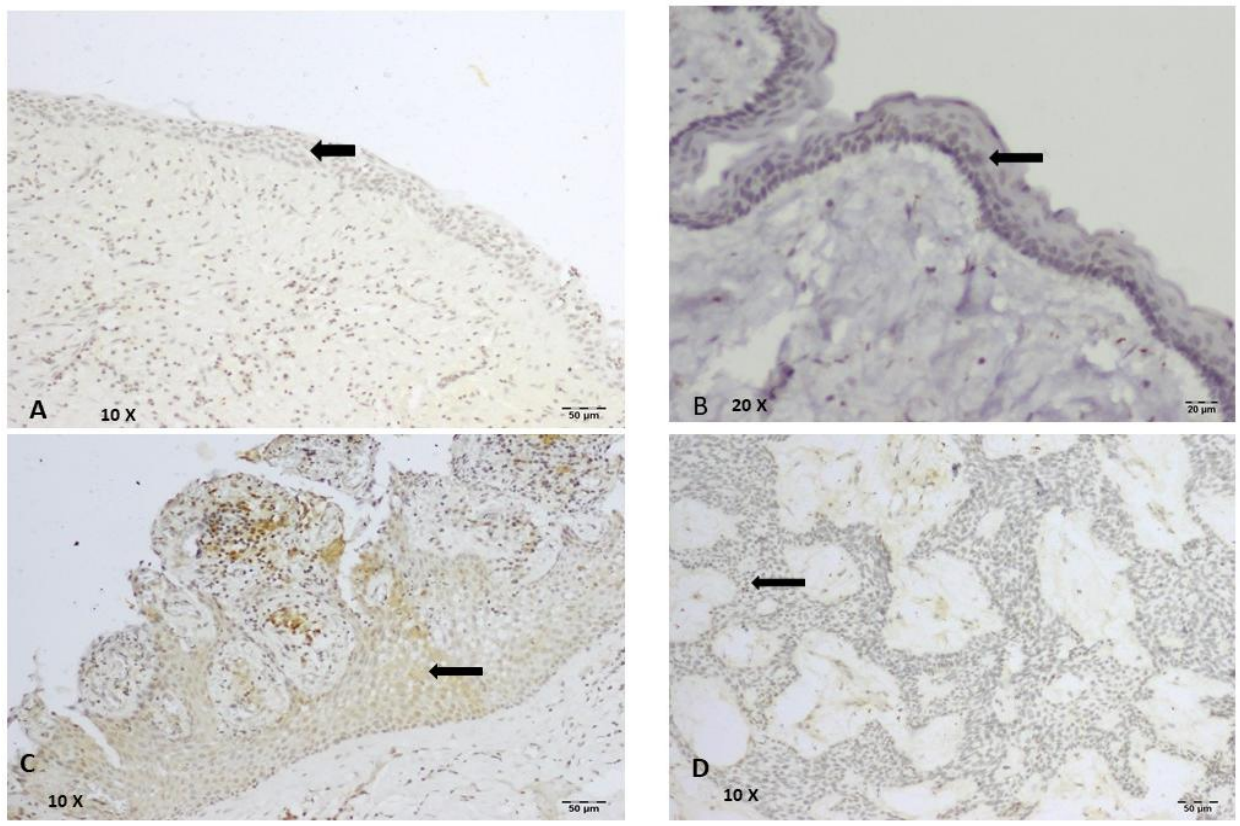

Fig 1. Expression of COX-2 in A. Dentigerous cyst, B. Odontogenic Keratocyst C. Radicular Cyst, D. Unicystic Ameloblastoma.

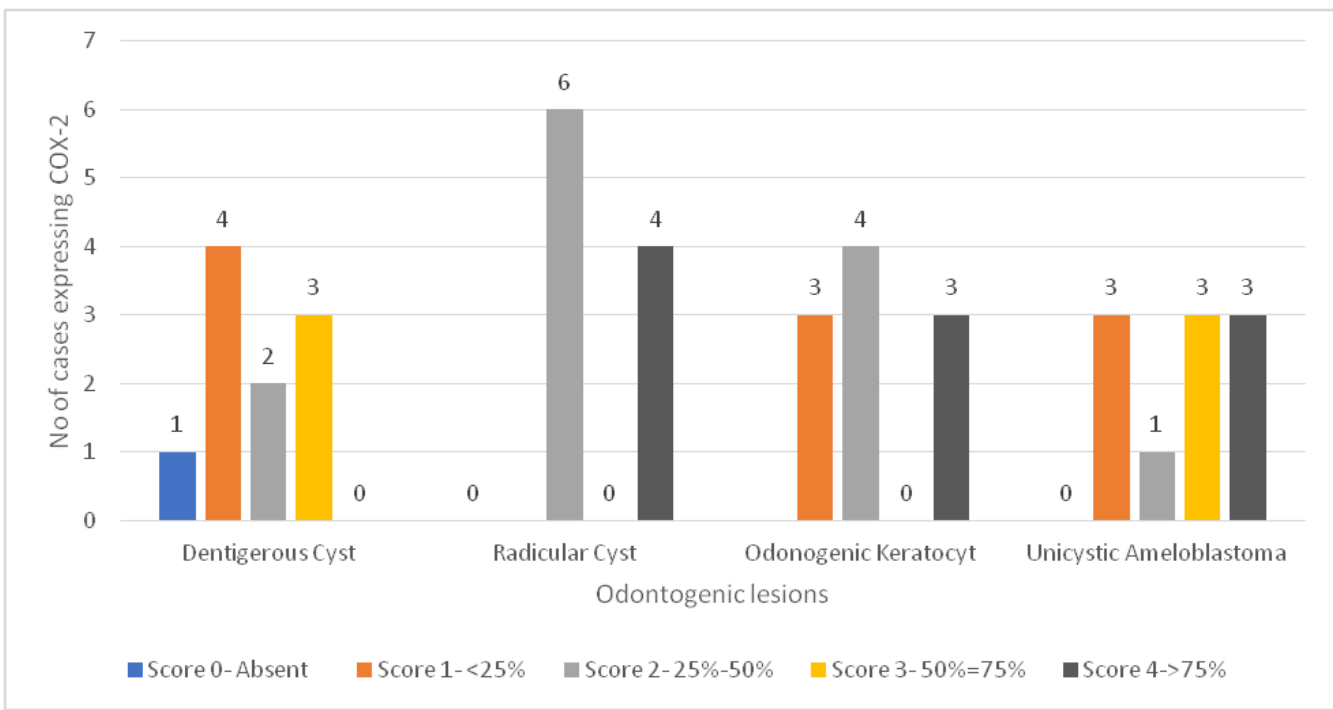

Fig 2. Comparison of the Percentage of COX-2 positive (Score) odontogenic epithelial cells in different odontogenic lesions

influence that COX-2 imparts on the proliferative activity of odontogenic epithelial cells. Dentigerous cysts develop due to accumulation of fluid (including glycosaminoglycan's) between reduced enamel epithelium of dental follicle and crown of unerupted teeth. In this study most of the Dentigerous cyst $(9 / 10=90 \%)$ showed that $25 \%-50 \%$ of the reduced enamel epithelial cells expressed COX-2. About $50 \%$ of the cysts showed a moderate intensity of the expression of COX-2. In the comparative study by Seyedmajidi et al only $5 / 15$ (33.3\%) of the dentigerous cyst expressed COX-2, but only one case showed a high expression for COX-2. In the study by 
Vol 10 No 1 (2022) Dol 10.5195/d3000.2022.205

Alsaegh et al 13/16 cases expressed COX-2 [16].

In the later stages of the clinical course of dentigerous cyst, bone resorption is a common feature. Prostaglandin E 2 is a vital molecule that stimulates or inhibits bone metabolism and can increase the number of functionally active osteoclasts [21]. An upregulation of COX-2 in the cells of the reduced enamel epithelium will induce the synthesis PGE2 and facilitate bone resorption. Kumamoto et al demonstrated that sonic hedge hog (SHH) signaling molecule is expressed by the odontogenic epithelial cells of the dentigerous cyst [22]. The SHH pathway through activation of Ras/Raf/ERK pathway can in turn induce the expression of COX-2 in these cysts $[16,23]$.

Radicular cysts are categorized as inflammatory odontogenic cysts that occur as a sequel to dental caries. The infection in the periapical area stimulates the cell rests of Malassez in the periapical region to proliferate and result in a cyst formation.

In this study the expression of COX2 was seen in more than $75 \%$ of the odontogenic rests in 4 out of the 10 cysts that were evaluated. Tsai et al in their study found that radicular cysts with more inflammation were associated with a high COX 2 expression.

Table 2. Comparison of the mean \% of positive odontogenic cells among the different odontogenic lesions

\begin{tabular}{|c|c|c|c|c|c|c|}
\hline \multirow[t]{3}{*}{ Odontogenic lesion } & \multirow{3}{*}{$\begin{array}{l}\text { Mean } \% \text { of } \\
\text { Positive } \\
\text { odontogenic cells }\end{array}$} & \multirow[t]{3}{*}{$\begin{array}{c}\text { Mean } \\
\text { Difference }\end{array}$} & \multirow[t]{3}{*}{$\begin{array}{l}\text { Std. } \\
\text { Error }\end{array}$} & \multirow[t]{3}{*}{$\begin{array}{l}\text { ANOVA } \\
\text { test }\end{array}$} & \multicolumn{2}{|c|}{$\begin{array}{c}\text { 95\% Confidence } \\
\text { Interval }\end{array}$} \\
\hline & & & & & Lower & Upper \\
\hline & & & & & Bound & Bound \\
\hline Dentigerous Cyst & $26.10 \pm 17.7$ & -30.600 & 10.683 & $.033^{*}$ & -59.37 & -1.83 \\
\hline Radicular Cyst & $56.70 \pm 23.6$ & & & & & \\
\hline Dentigerous cyst & $26.10 \pm 17.7$ & -22.400 & 10.683 & .174 & -51.17 & 6.37 \\
\hline Odontogenic Keratocyst & $48.50 \pm 26.2$ & & & & & \\
\hline Dentigerous cyst & $26.10 \pm 17.7$ & -30.900 & 10.683 & $.031^{*}$ & -59.67 & -2.13 \\
\hline Unicystic Ameloblastoma & $57 \pm 26.9$ & & & & & \\
\hline Radicular cyst & $56.70 \pm 23.6$ & 8.200 & 10.683 & .868 & -20.57 & 36.97 \\
\hline Odontogenic Keratocyst & $48.50 \pm 26.2$ & & & & & \\
\hline Radicular Cyst & $56.70 \pm 23.6$ & -300 & 10.683 & 1.000 & -29.07 & 28.47 \\
\hline Unicystic Ameloblastoma & $57 \pm 26.9$ & & & & & \\
\hline Odontogenic keratocyst & $48.50 \pm 26.2$ & -8500 & 10.683 & .856 & -37.27 & 20.27 \\
\hline Unicystic Ameloblastoma & $57 \pm 26.9$ & & & & & \\
\hline
\end{tabular}

*Significant association

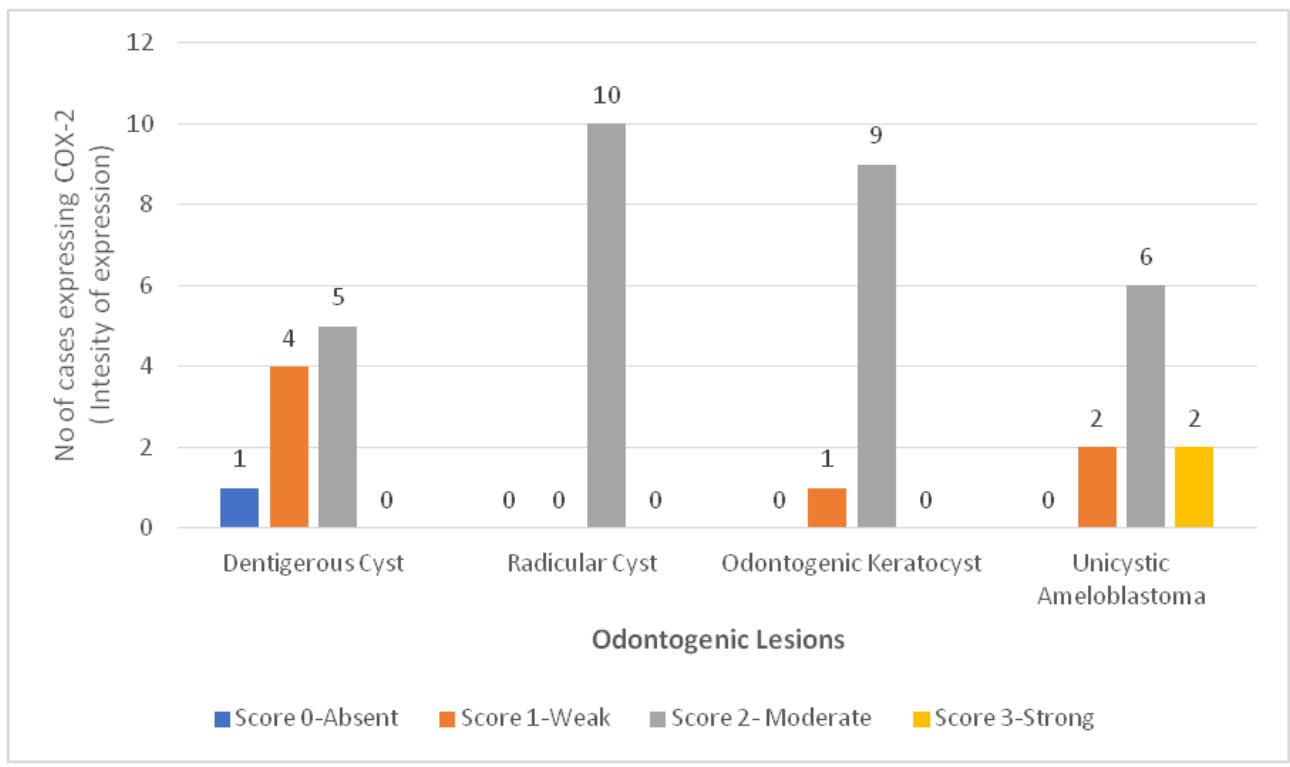

Fig 3. Comparison of the intensity of the expression of COX-2 by the odontogenic epithelial cells in different odontogenic lesions

In their study they found that COX-2 was expressed by the odontogenic epithelial layer, in the subepithelial fibroblasts, macrophages and endothelial cells [24].
In healthy tissue COX-2 is not detected or detected in only in low levels and is not expressed by normal epithelial or normal odontogenic epithelial cells. Growth factors, hormones and cytokines induce the expression of COX-2 [25, 26]. 


\section{口епடistrப ヨロ \\ Vol 10 No 1 (2022) DOI 10.5195/d3000.2022.205}

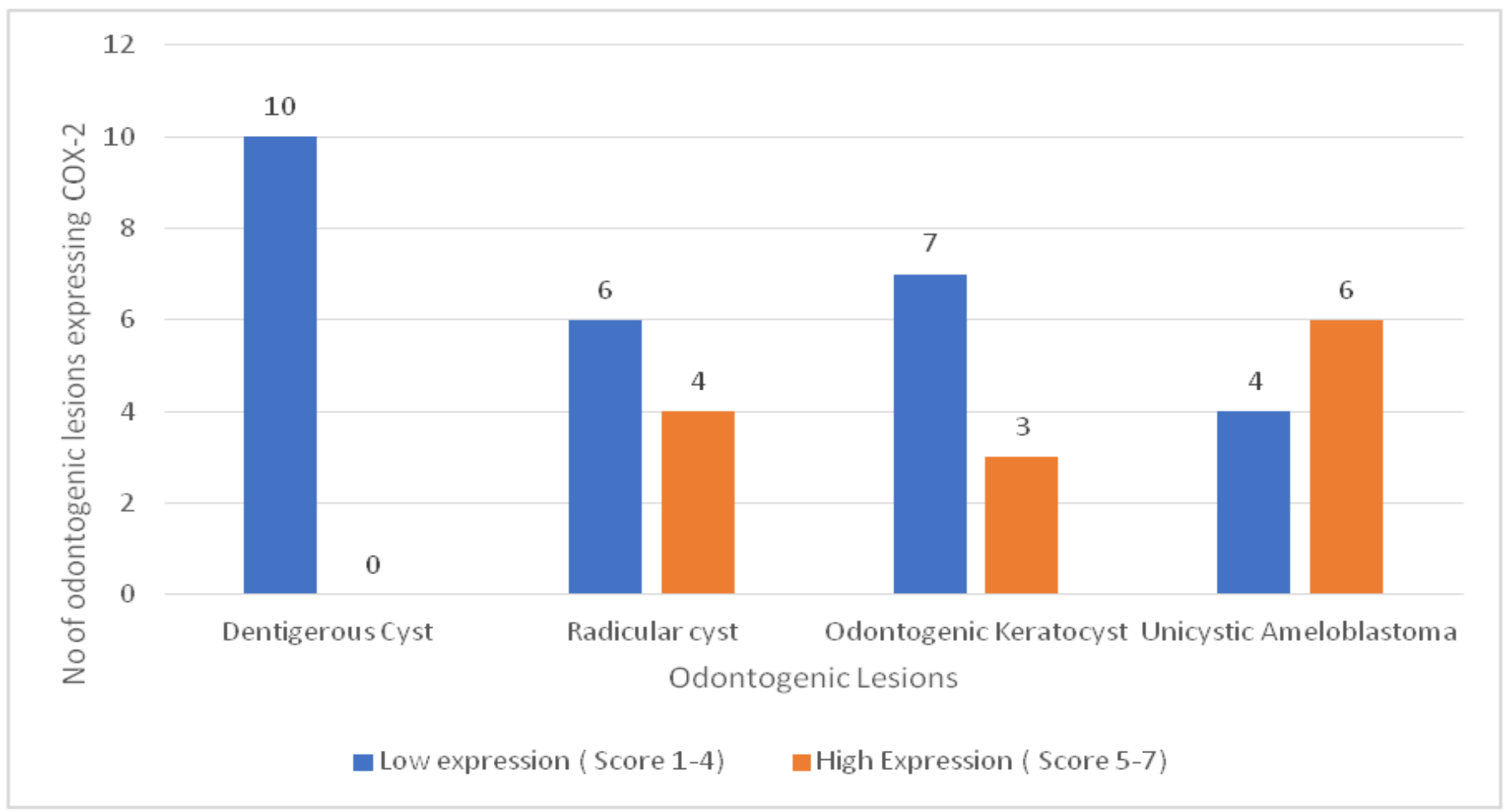

Fig 4. Comparison of the pattern of expression of COX-2 among the different odontogenic lesions.

During the inflammatory process there is an abundance of chemical mediators including tumor necrosis factor and interlukin-1. Interlukin 1 alpha has been found to increase the expression of COX-2 in fibroblasts [27]. When COX-2 expressed, it catalyzes the synthesis of prostaglandin from arachidonic acid [28].

Odontogenic keratocysts have a reputation of being aggressive in its clinical behaviour. In this study the expression of COX-2 was seen in more than $75 \%$ of the odontogenic cystic lining cells in $3 / 10$ (30\%) odontogenic keratocysts. Seyedmajidi, et al in their study found that all (15/15) of the odontogenic keratocyst that they evaluated, expressed
COX-2, but only $5 / 15$ (33\%) cysts showed a strong expression of COX2.They suggested that the COX-2 is a major acting marker in the aggressive behavior of odontogenic keratocysts [16].

In a study by Mendes et al all the 20 cases of odontogenic keratocysts that they evaluated expressed COX-2, and 18 of these 20 odontogenic keratocyst showed a strong expression of COX-2.
They also found that the cysts that showed a showed a strong expression of COX-2 also expresses $\mathrm{p} 53$ and $\mathrm{Ki}$ 67.COX-2 may contribute to the biological regulation of its epithelial lining [15]. In another study by Kaczmarzyk et al 37/41 odontogenic keratocyst that they evaluated expressed COX-2. They also found that the expression of COX-2 correlated with the expression of bcl2 in these odontogenic keratocysts [17].

Table 3. The association between the Odontogenic cysts and the expression (Total Score) of COX-2

\begin{tabular}{lllll}
\hline Odontogenic Lesions & \multicolumn{2}{c}{ Expression of COX-2 } & & \\
& $\begin{array}{l}\text { Low }(\%) \\
(\text { Score } 1-4)\end{array}$ & $\begin{array}{l}\text { High } n(\%) \\
(\text { Score 5-7) }\end{array}$ & $\mathrm{X}^{2}(\mathrm{df})$ & $\mathrm{p}$ Value \\
Dentigerous Cyst $(\mathrm{n}=10)$ & $10(100 \%)$ & $0(0 \%)$ & & \\
Radicular Cyst $(\mathrm{n}=10)$ & $6(60 \%)$ & $4(40 \%)$ & $4.845(2)$ & $0.031^{*}$ \\
Odontogenic Keratocyst $(\mathrm{n}=10)$ & $7(70 \%)$ & $3(30 \%)$ & & \\
\hline
\end{tabular}


口entistry $3 \square \square \square$

Vol 10 No 1 (2022) DOI 10.5195/d3000.2022.205

Among the Unicystic

ameloblastomas in 3/10 (33\%) cases

the expression of COX-2 was seen in more than $75 \%$ of the odontogenic epithelial cells. Earlier, studies have evaluated the expression of COX-2 in solid ameloblastoma than in unicystic ameloblastomas[13,15].

In the study by Seyedmajdi et al $3 / 15$ of the ameloblastomas showed a high expression of COX-2. They found that the pattern of expression of COX-2 in the ameloblastomas was similar to that of odontogenic keratocysts. But there was a significant difference between the expression of COX-2 in ameloblastomas and dentigerous cysts [16].

To validate the role of COX- 2 in proliferation of odontogenic epithelium, one case each of dentigerous cyst, radicular cyst, odontogenic keratocyst and unicystic ameloblastoma was immunohistochemically stained with Ki-67. The case of unicystic ameloblastoma and the case of odontogenic keratocyst stained positive for Ki-67, whereas Ki 67 was not expressed by the Radicular cyst and Dentigerous cyst (Figure 5). The association of COX-2 and Ki-67 in these odontogenic lesions will be evaluated in future.

This study along with other studies in literature strengthens the notion that COX-2 plays a vital role in confirming
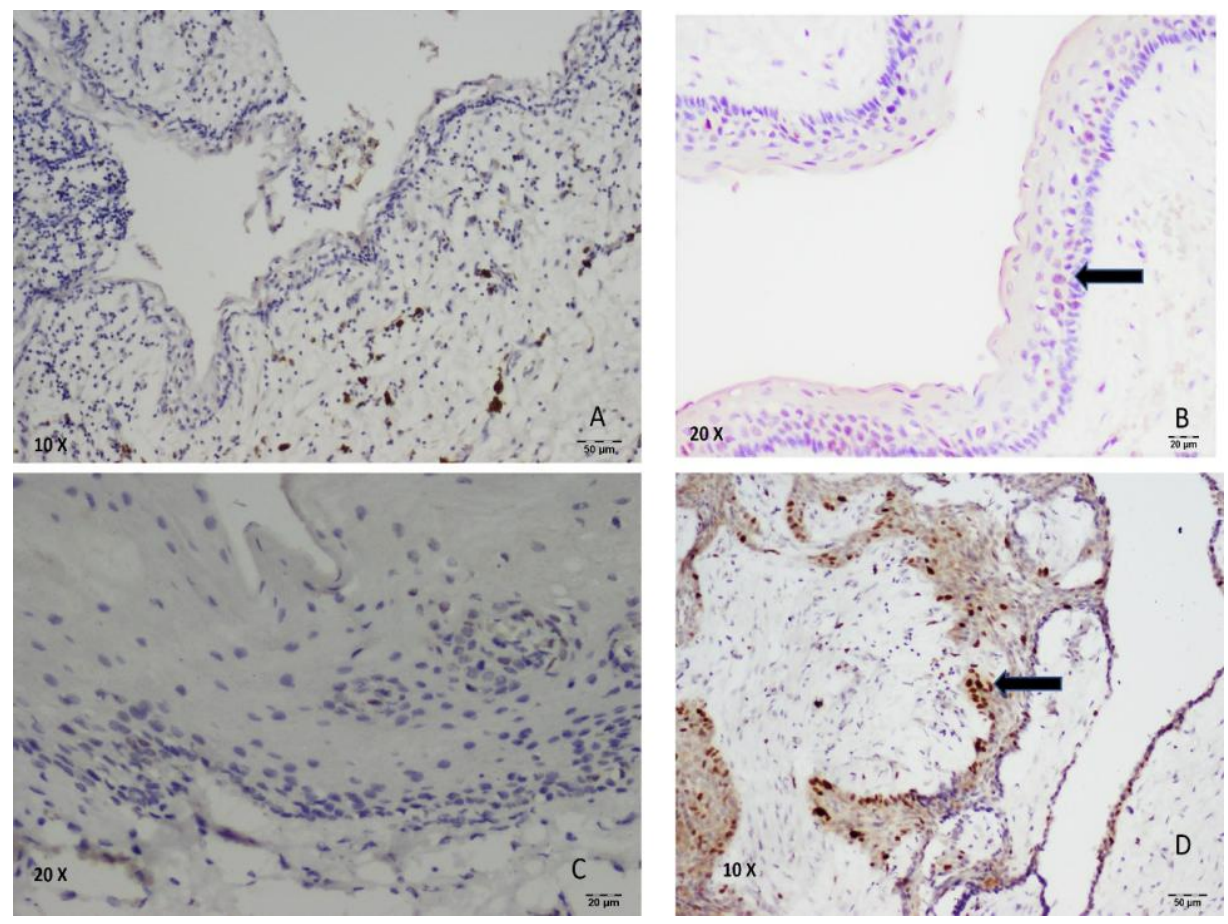

Figure 5. A. Dentigerous cyst (Absence of expression of Ki 67) B. Odontogenic Keratocyst (Ki-67 expression in the basal and supra basal cells of the odontogenic epithelial lining) $\mathbf{C}$. Radicular Cyst (No expression of Ki 67). D. Unicystic Ameloblastoma (Expression of Ki-67 by the ameloblast-like cells)

Table 4. Association of the expression of COX-2 (Total Score) among the different odontogenic Lesions

\begin{tabular}{|c|c|c|c|c|}
\hline \multirow[t]{2}{*}{ Odontogenic Lesions } & \multicolumn{2}{|c|}{ Expression of COX-2 } & \multirow[t]{2}{*}{$X^{2}(d f)$} & \multirow[t]{2}{*}{$p$ Value } \\
\hline & $\begin{array}{c}\text { Low score } \\
\begin{array}{c}(1-4) \\
\mathrm{n}(\%)\end{array}\end{array}$ & $\begin{array}{c}\text { High Score } \\
(5-7) \\
\mathrm{n}(\%)\end{array}$ & & \\
\hline Dentigerous Cyst ( $n=10)$ & $10(100 \%)$ & $0(0 \%)$ & \multirow{4}{*}{$8.547(3)$} & \multirow{4}{*}{$0.036^{*}$} \\
\hline Radicular Cyst ( $n=10)$ & $6(60 \%)$ & $4(40 \%)$ & & \\
\hline Odontogenic Keratocyst $(n=10)$ & $7(70 \%)$ & $3(30 \%)$ & & \\
\hline Unicystic Ameloblastoma & $4(40 \%)$ & $6(60 \%)$ & & \\
\hline
\end{tabular}

*Significant association

an aggressive nature to odontogenic lesions. As a limited number of COX-2 functions in the odontogenic epithelial cells. odontogenic lesions were evaluated in this study, further studies on a larger cohort of odontogenic lesions and by evaluating the expression of COX-2 with other proliferative markers is necessary to determine the molecular mechanism by which 


\section{Conclusion}

The present study evaluated the expression of COX-2 in the odontogenic lesions; Dentigerous cyst, Radicular cyst, odontogenic keratocyst and Unicystic ameloblastoma. The expression of COX-2 was higher in Radicular cyst, odontogenic keratocyst and Unicystic ameloblastoma compared to dentigerous cyst. COX-2 being an inflammatory marker, showed a high expression among the Radicular cysts. This study emphasizes the fact that COX-2 plays a vital role in biological behavior of odontogenic cysts and tumors. Thus, incorporating antiinflammatory medicaments and chemopreventive inhibitors of COX-2 will prove to be beneficial in the management of Radicular cysts, Odontogenic keratocysts and Unicystic ameloblastomas.

\section{Conflicts of interest}

The authors deny any conflicts of interest in regards to the current study.

\section{Acknowledgement}

Dr Aditi Deshpande for providing us with Cox-2 monoclonal antibody for the study.

\section{References}

1. Shear M, Speight $P$, Shear M. Cysts of the oral and maxillofacial regions. Oxford: Blackwell Pub.; 2007.

Table 5. Association of the expression of COX-2 (Total Score) and risk ratio among the odontogenic lesions

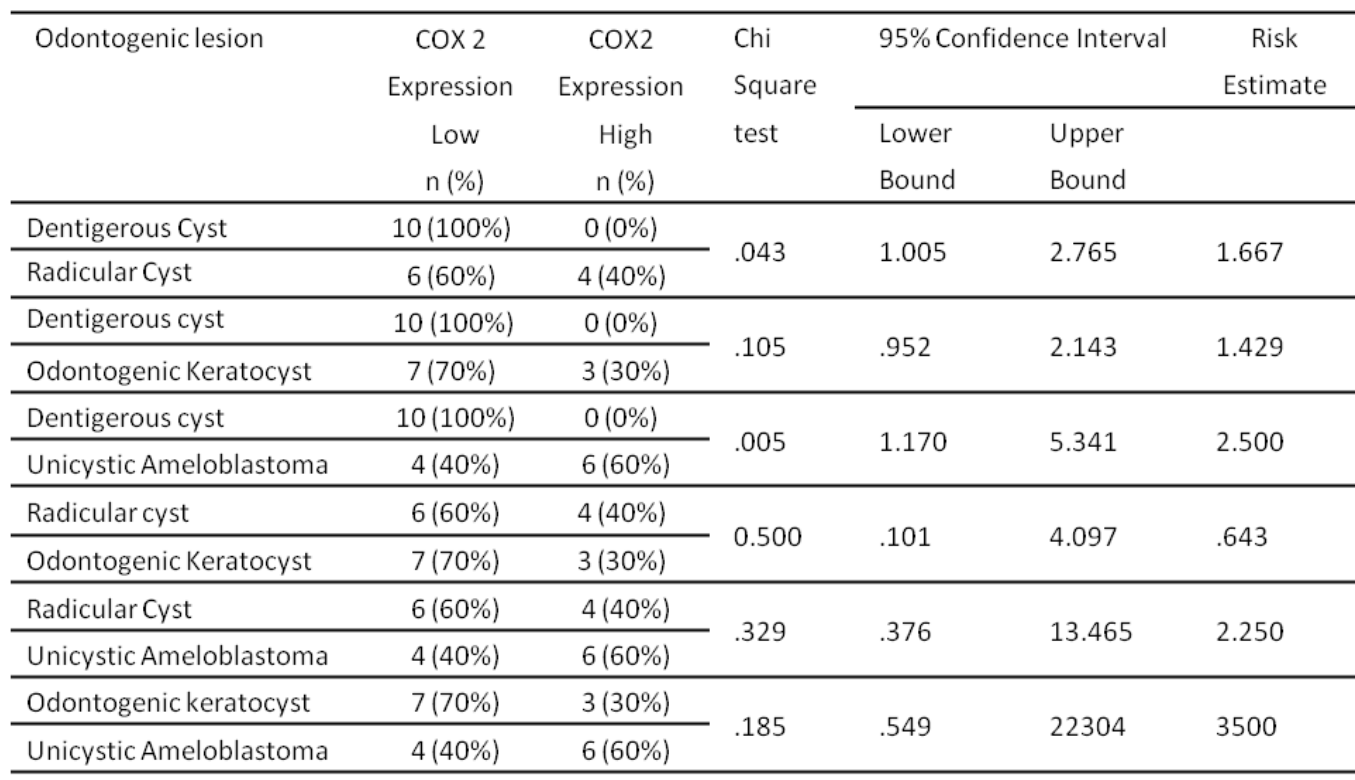

2. Speight $P$. Odontogenic and nonodontogenic developmental cysts. In: El -Naggar AK, Chan JKC, Grandis JR, Takata T, Slootweg PJ, eds. WHO Classification of Head and Neck Tumours, 4th edn. Lyon: World Health Organization. 2017;234-242.

3. Radicular cyst of the anterior maxilla: An insight into the most common inflammatory cyst of the jaws. Koju S, Chaurasia NK, Marla V, Niroula D, Poudel P. J Dent Res Rev 2019; 6: 26-29

https://www.jdrrrg/text.asp

4. Does cytokine profiling of aspirate from jaw cysts and tumors have a role in diagnosis? Kolokythas $\mathrm{A}$, Karas $\mathrm{M}$, Sarna T, Flick W, Miloro M J Oral Maxillofac Surg. 2012 70(5):1070- 80. DOI: 10.1016/j.joms.2011.04.003

5. Cysts of the orofacial region, Shafer's textbook of oral pathology 9th Edition, Adaptive Editor
Sivapathasundaram, Elsevier Page No 72-5.

6. Unicystic ameloblastoma: a clinicopathologic study of 33 Chinese patients. Li TJ, Wu YT, Yu SF, Yu GY. Am J Surg Pathol. 2000 Oct;24(10):1385-92. DOI: 10.1097/00000478-200010000-00008

7. Prostaglandin endoperoxidase $\mathrm{H}$ synthase (Cyclooxygenases)- 1 and 2. Smith WL, Garavito RM, DeWitt DL. J Biol Chem 1996; 271: 3157-60. DOI: 10.1074/jbc.271.52.33157

8. The cyclooxygenases. Chandrasekharan NV and Simmons DL. Genome Biol 2004; 5:241 DOI: 10.1186/gb-2004-5-9-241

9. The role of COX-2 in intestinal inflammation and colorectal cancer.Wang D, Dubois RN. Oncogene 2010; 29: 781-789. DOI: 10.1038/onc.2009.421 
10. Inducible isoforms of

cyclooxygenase and nitric oxide

synthase in inflammation. Van JR, Mitchell JA, Appelton I, Tomlinson A, Bishop -Bailey D, Croxtall X et al Proc Natl Acad Sci USA 1994; 91(16): 20462050. DOI: 10.1073/pnas.91.6.2046

11. Alteration in cellular adhesion and apoptosis in epithelial cells overexpressing prostaglandin endoperoxidase synthase 2. Tsujii M, DuBois RN. Cell 1995; 83 (3): 493-501. DOI: 10.1016/0092-8674(95)90127-2

12. Cyclooxygenase regulates angiogenesis induced by colon cancer cells. Tsujii M Kawano S, Tuji S Sawaoka H, Hori M, DuBois RN. Cell 1998; 93 (5); 705-716 DOI: 10.1016/s0092-8674(00)81433-6

13. Deregulated Cyclooxygenase -2 expression in oral permalignant tissues. Banerjee AG, Gopalkrishnan VK, Bhattacharya I, Vishwanatha JK. Mol Cancer Ther I 2002; 1265- 1271.

14. Odontogenic epithelial proliferation is correlated with COX-2 expression in dentigerous cyst and ameloblastoma. Alsaegh MA, Miyashita H, Taniguchi T, Zhu SR. Experimental and therapeutic medicine 2017;13: 247-253. DOI: 10.3892/etm.2016.3939

15. A comparative immubohistochemical analysis of COX-2, p53, and Ki 67 expression in Keratocystic odontogenic tumors. Mendes RA Carvalho JFC, Van der Waal I. Oral Surg Oral Med Oral Path Oral Radiol Endod 2011; 111(3): 333-
339.DOI:

10.1016/j.tripleo.2010.10.004

16. Immunohistochemical analysis of COX-2 expression in dentigerous cyst, keratocystic odontogenic tumor and ameloblastoma: A comparative study. Seyedmajidi M, Shafaee S, Siadati S, Moghaddam EA, Ghasemi N, Bijani A et al.Dent Res J 2015;12(3):278-284.

17. Investigation of

clinicopathological parameters and expression of COX-2, bcl-2, PCNA, and p53 in primary and recurrent sporadic odontogenic keratocyst. Kaczmarzyk T, Kiselowski K, Koszowski R, Rynkiewicz M, Gawelek E, Babiuch K et al. Clin Oral Invest 2018; 22: 3097106. DOI: $10.1007 / \mathrm{s} 00784-018-2400-$ 7

18. Expression of cyclooxygenase-2 in prostate carcinoma. Yoshikawa $\mathrm{R}$, Sano H, Masuda C, Kawamura M, Tsubouchi Y, Chargui J et al Cancer 2000;89(3):589-596.

19. Cyclooxygenase-2 expression in endometrial cancer: correlation with microvessel count and expression of vascular endothelial growth factor and thymidine phosphorylase. Fujiwaki R,lida K, Kanasaki H, Ozaki T, Hata K, Miyazaki K. Human Pathology 2002; 33(2):213-219. DOI:

10.1053/hupa.2002.31292

20. Modulation of apoptosis and $\mathrm{Bcl}-2$ expression by prostaglandin E2 in human colon cancer cells. Sheng $\mathrm{H}$, Shao J, Morrow JD, Beauchamp RD, DuBois RN. Cancer Res 1998; 58(2):362- 366
21. Prostaglandin and bone: potential risks and benefits related to the use of nonsteroidal anti- inflammatory drugs in clinical dentistry Francon RN, Teofilo JM, satin RB and Lamano TJ. Oral Sci 2008; 50:247-52. DOI: 10.2334/josnusd.50.247

22. Expression of Sonic hedgehog (SHH) signaling molecules in ameloblastomas. Kumamoto $\mathrm{H}$, Ohki K, Ooya K. J Oral Pathol Med 2004; 33: 185-190.DOI: 10.1111/j.09042512.2004.00070.x

23. p53 mediated induction of COX-2 counteracts p53 or genotoxic stress induced apoptosis. Han JA, Kim JL, Ongusaha PP, Hwang DH, Ballou LR, Mahale A et al. EMBO J 2002;

21:5635- 5644.

DOI:10.1093/emboj/cdf591

24. Immunohistochemical localization of cyclooxygenase-2 in radicular cysts. Tsai CH, Huang FM, Yang LC, Chou MY, Chang YC. Int Endod J. 2002 Oct; 35(10):854-858. DOI: 10.1046/j.13652591.2002.00584.x

25. Cyclooxygenase in biology and disease. Dubois RN, Abramson SB, Crofford L, Gupta RA, Simon LS, Van De Putte LB et al. FASEB J. 1998 Sep; 12(12):1063-1073.

26. Update on oral lichen planus: etiopathogenesis and management. Scully C, Beyli M, Ferreiro MC, Ficarra G, Gill Y, Griffiths M et al Crit Rev Oral Biol Med 1998;9(1):86-122. DOI: 10.1177/10454411980090010501

27. Signaling pathways regulating IL-1 alpha induced COX-2 expression. 
vol 10 No 1 (2022) Dol 10.5195/d3000.2022.205

Ogata S, Kubota Y, Yamashiro T, Takeuchi H, Ninomiya T, Suyuma $Y$ et al. J Dent Res 2007; 86: 186-91. DOI:

$10.1177 / 154405910708600215$

28. Cyclooxygenase 2 and carcinogenesis. Prescott SM, Fitzpatrick FA, Biochem Biophys Acta 2000; 1470:69-78.DOI:

10.1016/s0304-419x(00)00006-8 